\title{
Childhood parasitic infections and gastrointestinal illness in indigenous communities at Lake Atitlán, Guatemala
} \author{
Caballeros Barragán $^{7}$, Lujain Al-Saleh ${ }^{8}$, Eliška Rejmánková ${ }^{2}$ \\ ${ }^{1}$ Center For Global Health, University of Oregon, Eugene, OR, United States \\ 2 Department of Environmental Science and Policy, University of California, Davis, Davis, CA, United States \\ 3 Center for Atitlán Studies, Universidad del Valle de Guatemala, Sololá, Sololá, Guatemala \\ 4 Center for Health Studies, Universidad del Valle de Guatemala, Sololá, Sololá, Guatemala \\ 5 Opal House, Agua Escondida, Sololá, Guatemala \\ 6 Unaffiliated, Sololá, Sololá, Guatemala \\ 7 Laboratorio La Asunción, Sololá, Sololá, Guatemala \\ 8 School of Public Health, University of California, Berkeley, Berkeley, CA, United States \\ Corresponding Author: Amber Roegner \\ Email address: afroegner@gmail.com
}

Amber Roegner ${ }^{\text {Corresp., } 1,2 \text {, Mónica N Orozco }}{ }^{3}$, Claudia M Jarquin ${ }^{4}$, William Boegel ${ }^{5}$, Clara Secaira $^{6}$, Marlin

Lake Atitlán has experienced a decline in water quality resulting from cultural eutrophication. Indigenous Mayans who already face disproportionate health challenges rely directly on the lake water. Our objectives were to: 1 ) estimate prevalence of shedding of water-borne fecal parasites among children 5 years of age and younger, 2) assess household-reported incidence of gastrointestinal illness in children, and 3) characterize water sources, treatment, and sanitation conditions in households. We hypothesized that household use of untreated lake water results in increased risk of shedding of parasites and gastrointestinal symptoms. A cross-sectional fecal sampling and physical exam of 401 children were conducted along with WASH surveys in partnership with healthcare providers in seven communities. Fecal samples were screened for Giardia lamblia and Cryptosporidium parvum, using a rapid ELISA, with a portion examined by microscope. The prevalence of parasite shedding was $12 . .2 \%$ (9.7\% for Giardia; $2.5 \%$ for Cryptosporidium). Risk factors for Giardia shedding included age 3 years or older (3.4 odds ratio, z-stat $=2.781 p=0.0054$ ), low height-for-age $z$-score ( 2.3 odds ratio, $z$-stat $=2.225, p=$ 0.0216 ), lack of any household water treatment ( 2.5 odds ratio, z-stat $=2.492, p<$ $0.0012)$, and open access to household latrine ( $O R=2.04$, z-stat $=1.992, p=0.0464)$. The majority (77.3\%) of households reported water treatment, boiling and gravity fed filters as the most widespread practices. The vast majority of households (92\%) reported usage of a latrine, while $40 \%$ reported open and shared access beyond their household. An overwhelming majority of households reported diarrhea and fever several times per year 
or greater, with approximately half reporting vomiting at that frequency. Lake water use was identified as a risk factor for households reporting frequent gastrointestinal symptoms (odds ratio risk of $2.5,4.4$, and 2.6; z-stat of 3.10, 3.65, and 3.0; p-values of 0.0021 , 0.0003 , and 0.0028 , for diarrhea, vomiting, and fever, respectively) in children 5 years of age and younger. The frequency of gastrointestinal illness with a strong link to lake drinking water cannot be explained by the prevalence of protozoa, and risk from other enteropathogens must be explored. Improving access to water treatment and sanitation practices could substantially reduce the parasite burden faced by developing children in the region. 
2 Childhood parasitic infections and gastrointestinal illness in indigenous communities at Lake Atitlán, Guatemala

4 Amber Roegner ${ }^{1 \# a}$, Mónica N. Orozco ${ }^{2}$, Claudia M. Jarquin ${ }^{3}$, William Boegel ${ }^{4}$, Clara Secaira $^{5}$, Marlin Caballeros Barragán ${ }^{6}$, Lujain Al-Saleh$^{7}$, Eliška Rejmánková1 $^{1}$

$6{ }^{1}$ Department of Environmental Science and Policy, University of California, Davis, CA, USA

$7 \quad 2$ Center for Atitlán Studies, Universidad del Valle de Guatemala, Sololá, Guatemala

$8{ }^{3}$ Center for Health Studies, Universidad del Valle de Guatemala, Sololá, Guatemala

$9{ }^{4}$ Opal House Children's Mission, Agua Escondida, Sololá, Guatemala

$10{ }^{5}$ Independent Consultant at Lake Atitlán, Sololá, Guatemala

$11{ }^{6}$ Laboratorio La Asunción, Sololá, Guatemala

$12{ }^{7}$ School of Public Health, University of California, Berkeley, CA, USA

13 Corresponding Author:

14 Amber Roegner

15 Center for Global Health, University of Oregon, Eugene, OR, 97405, USA

16 Email address: afroegner@gmail.com

\section{Abstract}


30

eutrophication. Indigenous Mayans who already face disproportionate health challenges rely

directly on the lake water. Our objectives were to: 1) estimate prevalence of shedding of waterborne fecal parasites among children 5 years of age and younger, 2) assess household-reported incidence of gastrointestinal illness in children, and 3) characterize water sources, treatment, and sanitation conditions in households. We hypothesized that household use of untreated lake water results in increased risk of shedding of parasites and gastrointestinal symptoms. A crosssectional fecal sampling and physical exam of 401 children were conducted along with WASH surveys in partnership with healthcare providers in seven communities. Fecal samples were screened for Giardia lamblia and Cryptosporidium parvum, using a rapid ELISA, with a portion examined by microscope. The prevalence of parasite shedding was $12 . .2 \%(9.7 \%$ for Giardia; 2.5\% for Cryptosporidium). Risk factors for Giardia shedding included age 3 years or older (3.4 odds ratio, $\mathrm{z}$-stat $=2.781 \mathrm{p}=0.0054)$, low height-for-age $\mathrm{z}$-score $(2.3$ odds ratio, $\mathrm{z}$-stat $=2.225, \mathrm{p}$ $=0.0216)$, lack of any household water treatment $(2.5$ odds ratio, $z$-stat $=2.492, \mathrm{p}<0.0012)$, and open access to household latrine $(\mathrm{OR}=2.04, \mathrm{z}$-stat $=1.992, \mathrm{p}=0.0464)$. The majority $(77.3 \%)$ of households reported water treatment, boiling and gravity fed filters as the most widespread practices. The vast majority of households (92\%) reported usage of a latrine, while $40 \%$ reported open and shared access beyond their household. An overwhelming majority of households reported diarrhea and fever several times per year or greater, with approximately half reporting vomiting at that frequency. Lake water use was identified as a risk factor for households reporting frequent gastrointestinal symptoms (odds ratio risk of 2.5, 4.4, and 2.6; z-stat of 3.10, 3.65, and 3.0; p-values of $0.0021,0.0003$, and 0.0028 , for diarrhea, vomiting, and fever, respectively) in children 5 years of age and younger. The frequency of gastrointestinal illness 
52 with a strong link to lake drinking water cannot be explained by the prevalence of protozoa, and

53 risk from other enteropathogens must be explored. Improving access to water treatment and

54 sanitation practices could substantially reduce the parasite burden faced by developing children

55 in the region.

\section{Introduction}

57

58

74 (Chandra et al., 2013). The persistent entry of raw sewage into the lake, estimated at $45,000 \mathrm{~m}^{3}$ 
75 per day, has resulted in direct fecal contamination (Ferráns et al., 2018; Orozco, 2017; Roegner

76 et al., 2016). At least five lakeside towns draw a portion of municipal water directly from the

77 lake. Chlorination is mandated by government code, although enforcement is absent, and

78 previous anthropological work has suggested variable distrust of chlorination among the Mayan

79 populations (Nagata et al., 2011; Orozco, 2017). In lake waters, there is repeated evidence of

80 degraded water quality with elevated coliforms and E. coli at intake, point sources, and nonpoint

81 sources (Castellanos et al., 2002), and 24\% of monitored drinking water facilities, although many

82 go unmonitored, deliver unacceptable levels of bacterial contamination (Ferráns et al., 2018;

83 INE, 2018; Orozco, 2017).

84 The indigenous population in Guatemala is heterogenous with three dominant ethnicities

85 in the Sololá Department, K'iche', Kaqchikel, and Tz'utujil, the latter two predominant in the

86 basin. They face disproportionate health risks compared to the non-indigenous (Chen et al.,

87 2017; Jensen et al., 2009; Nagata et al., 2011; Nagata et al., 2009). Worldwide, indigenous

88 communities face increased health risks alongside lack of access to health care and poverty

89 (MSPAS, 2019; Omarova et al., 2018; Poder and He, 2015). Over 70\% of the indigenous

90 population in the Sololá Department live in extreme poverty (Omarova et al., 2018; Poder and

$91 \mathrm{He}, 2015)$. They constitute the majority of individuals directly utilizing lake water in the region.

92 Within the department of Sololá, there were 28,041 and 32,724 severe diarrheal cases in children

$93<5$ years of age (rate of 5251.47 and 5967.79 per 100,000 inhabitants) during 2018 and 2019,

94 respectively (MSPAS, 2019). There have been few studies looking at prevalence of waterborne

95 illness in the region, although 11.2 deaths per 100,000 inhabitants in Sololá department and

96 nationwide in Guatemala were related to gastroenteritis and other infectious colitis in 2017 (INE,

97 2018; INE, n.d). One study in 2004 found that 32\% of residents from two villages at Atitlán had 
98 Cryptosporidium parvum infections, with the highest prevalence among female children and

99 increased risk among those with a contaminated water supply from the lake (Laubach et al.,

100 2014). Abdominal pain and diarrhea in school age children between ages 2 to 13 has been

101 strongly correlated with shedding of Cryptosporidium oocysts in the region (Bentley et al., 102 2004).

103 Intestinal protozoa, such as Cryptosporidium and Giardia, cause symptomatic diarrhea

104 and represent a frequently neglected public health risk with both among leading causes of

105 moderate to severe diarrhea in children (Bentley et al., 2004). They also threaten development

106 through prolonged inflammation and oxidative stress in the gut lining, particularly for infants and

107 developing children, even in asymptomatic individuals (Certad et al., 2017; Mmbaga and Houpt,

108 2017). Prolonged disruption of the gut-lining results in inflammatory bowel disease and

109 malabsorption. By substantially altering gut health, dietary intake and nutrients available to

110 pregnant or nursing mother and child, it also directly impacts growth and cognitive development

111 (Certad et al., 2017; Mmbaga and Houpt, 2017; Mohammadkhah et al., 2018). Guatemala has

112 one of the highest levels of stunting among children under 5 years of age in the world, close to

$11350 \%$. Previous work in the region has linked malabsorption and evidence of systemic oxidative

114 stress (Solomons et al., 2015; Soto-Méndez et al., 2017; Soto-Méndez et al., 2016), as well as

115 parasitic intestinal infections, to retarded growth curves in infants and preschool aged children

116 (Farthing et al., 1986). Indeed, a retrospective study of 10,586 children of ages 5-15 in

117 Guatemala over a four-year period (2004-2007) found increased risk of severe malnutrition with

118 infection with Giardia lamblia and Entamoeba histolytica (Jensen et al., 2009). Systemic and

119 urinary biomarkers of oxidative stress in preschoolers in the western highlands have been

120 strongly correlated with Giardia infections (Soto-Méndez et al., 2016). Thus, not only are 
121 intestinal protozoa of immediate concern for symptomatic diarrhea and public health, but also for

122 the long-term developmental consequences for children in the region.

123 Given chronic health implications of protozoal infection in young children, the raw

124 sewage going directly in the lake, and multifactorial health risks and disproportionate poverty in

125 indigenous populations, we aimed to examine linkages between indigenous household water

126 sources and water, sanitation, hygiene (WASH) practices, gastrointestinal illness, and fecal

127 protozoal parasites. Our objectives were to: 1) estimate prevalence of shedding of most common

128 fecal parasites of human origin (Giardia lamblia, Cryptosporidium parvum and Entamoeba

129 histolytica) among children 5 years of age and younger in communities around Lake Atitlán, 2)

130 assess household-reported incidence of gastrointestinal illness in those children, and 3)

131 characterize water sources, any treatment of water, and sanitation conditions for households with

132 children 5 years old and younger. We hypothesized that household use of untreated lake water

133 would result in increased risk of shedding of parasites and household-reported disease.

134 Materials \& Methods

135 Overall study design

136 To determine the prevalence of fecal parasite shedding in children under 5 years of age 137 and obtain information on water sources, household treatment, and sanitation conditions in the 138 home, a cross-sectional fecal sampling and WASH survey of 401 children was conducted in 139 partnership with local NGOs and participating local physicians and health care providers (see 140 Acknowledgements). With a goal of 400 subjects distributed equally between spring and lake 141 water sources, subjects were recruited from seven communities around the lake, four of which 142 were known to draw the majority or a portion of municipal water from the lake directly (San

143 Lucas Tolimán, Santiago Atitlán, San Pedro La Laguna, and Panajachel), and three with 
144 mountain-derived spring water sources San Jorge de La Laguna, Tierra Linda, and Agua

145 Escondida). Fecal samples were kept refrigerated, collected within 24 hours of study

146 participation, and analyzed within 24 hours.

147 Subject recruitment \& consent

148 In September through November 2017, families with children 5 years old or younger

149 were recruited to participate. Recruitment occurred through clinics, nurseries, and primary health

150 providers in the region, as a part of routine check-ups, drop-in services, vaccination clinics, or

151 group health and educational activities. Human subject approval and work with sensitive subjects

152 (children) was approved through the Institutional Review Board at University of California,

153 Davis (IRB \# 1070493-3) and through the Comité de Ética en Investigación of the Centro de

154 Estudios en Salud (CEI-CES) at Universidad del Valle de Guatemala (No. Protocol 167-07-

155 2017).

156 Parents or guardians were asked to provide written informed consent, translated to

157 Spanish or local language, before participating in any study activities. Prior to the day of

158 participation, parents or guardians were given a sterile container for collection of feces from

159 children, which they were instructed to collect and return within 24 hours to the clinic to initiate

160 participation in the study. To compensate study participation, parents were provided with a free

161 bag of the nutritional, plant-based protein-rich beverage for infants and young children

162 (Incaparina $\left.{ }^{\circledR}\right)$. They also received educational training in how to reduce risks for their children

163 and others in their family from water borne diseases, including information on water treatment

164 options (Appendix A). In addition, where applicable, positive fecal test results were relayed to

165 health care providers within one week and delivered to study participants, along with the 
166 appropriate medication. Appendix B details the medication treatment regimen included in the 167 study.

168 Questionnaire, physical exam, and sample collection

169 Single visit study participation included a WASH questionnaire (Appendix C)

170 administered to parent or guardian by study personnel, a physical exam performed by the facility

171 physician with data noted by multilingual assistant (Appendix D), and submission of collected

172 stool samples for laboratory analysis. Prior to initiation of visits, all participating physicians and

173 study personnel underwent training for human subjects and confidentiality, as well as a thorough

174 overview of protocol, study objectives, and design. Inclusion criteria included any children ages

1755 years of age or younger living in lakeside communities within the department of Sololá, who

176 sought care at participating clinics and whose parents or guardians provided informed written

177 consent. Exclusion criteria included age older than 5 years, acute sickness beyond possible

178 physical examination as determined by attending physician, absence of consent from

179 parent/guardian or child, unwillingness to provide a stool sample, or children suffering from

180 confounding allergic diseases, such as irritable bowel disease, Crohn's disease, food allergies,

181 and Celiac disease, per previous clinical record or diagnosis. Children were not excluded nor

182 actively included based on presence or absence of episodic cases of gastrointestinal symptoms if

183 no specific diagnoses had been made by their healthcare provider.

184 Collection of stool sample and transport

185 During recruitment, the participant's parent or guardian was provided with sterile gloves 186 and a specimen collection container, and instructions on how to collect a stool sample. Submitted

187 fecal specimens were placed inside a plastic bag and samples in coolers were transported within 188 hours to Laboratorio La Asunción, Sololá. Fecal samples were only analyzed if they were fresh 
189 samples or collected within the last 24 hours with community healthcare liaison and health care

190 providers verifying timeline. If fecal samples were not collected within 24 hours, the patient data

191 was excluded from the study.

192 Fecal laboratory analysis

193 The samples were screened for Giardia and Cryptosporidium using the

194 GIARDIA/CRYPTOSPORIDIUM CHEK® (heretofore, 'Chek') (sensitivity 98.4\%, specificity

$195100 \%$, by independent study) (Youn et al., 2009) according to manufacturer instructions

196 (TECHLAB 2016, ALERE, Blacksburg, VA). The ELISA method relies on monoclonal and

197 polyclonal antibodies to detect cell-surface antigens of the Giardia cyst or Cryptosporidium

198 oocyst in human fecal samples. Samples were brought to room temperature and diluted with

199 diluent at a $4: 1$ ratio ( $400 \mu 1$ of diluent and $100 \mu 1$ or 0.1 gram of feces), in a microcentrifuge

200 tube, then mixed thoroughly with a vortex. After the addition of $100 \mu \mathrm{l}$ in each well of the

201 microtiter plate, $50 \mu \mathrm{l}$ of control or sample was added to each well; following a series of

202 incubation and washing step, the samples were read in an ELISA plate reader at $450 \mathrm{~nm}$ or

$203450 / 620 \mathrm{~nm}$.

204 For a subset of samples (140/401), the TRIAGE MICROPARASITE PANEL (heretofore,

205 'Triage') (ALERE, Blacksburg, VA) was used for simultaneous detection of Giardia lamblia,

206 Cryptosporidium parvum, and Entamoeba histolytica/dispar, following manufacturer's

207 instructions. Briefly, the method consists of a color change reaction that involves the application

208 of $500 \mu \mathrm{l}$ of microcentrifuged filtered sample, from an initial $500 \mu \mathrm{l}$ fecal samples dissolved in

$2094.5 \mathrm{ml}$ diluent, to a panel, followed by addition of a conjugate, incubation step, a washing step,

210 and addition of a substrate, read after five minutes. Provided all three control lines appeared

211 within the test zone, a color bar of any intensity appearing with the sample test zones, indicates

Peer] reviewing PDF | (2021:01:57049:1:1:NEW 18 Aug 2021) 
212 presence of those organisms. Additionally, a randomly selected subset (268/401) were screened

213 by laboratory personnel through the microscope, after performing a fecal float and smear

214 (Broussard, 2003).

215 Data analysis

216 Raw data and specimens were archived only for the duration of the study. Analysis of

217 anonymized and coded survey and physical examination data was undertaken with the assistance

218 of RStudio ${ }^{\circledR}$ opensource software (RStudio Team, 2017). Z-scores and age-weighted BMIs were

219 calculated according to World Health Organization guidelines. Descriptive statistics were used

220 initially to characterize the physical exam data and WASH questionnaire, as well as to describe

221 the prevalence of shedding of fecal parasites overall, and later relative to gender, community,

222 water sources, and z-scores and WHO-adjusted BMI. Student t-tests and an ANOVA were used

223 to look for potential differences between genders and communities, respectively.

224 In addition, logistic regression and chi square analysis of various categorical variables,

225 utilizing a 95\% confidence interval and with a p-value significance of less than or equal to 0.05 ,

226 with respect to adverse health outcome (positive fecal sample or frequently reported symptoms)

227 were systematically carried out to test various hypotheses relative to household water source,

228 treatment, hygiene, and sanitation practices. Subsequently, for identified risk factors, odds ratios

229 were determined for each participant characteristics and household practices or outcomes of

230 protozoa shedding or gastrointestinal symptoms.

\section{Results}

232

Descriptive characteristics of study participants

A total of 401 participants were enrolled in the study, with 215 males and 186 females

234 after exclusion and inclusion criteria were applied. Figure 1 illustrates distribution of male and 
235 female participants at each site around the lake. San Lucas Tolimán, Santiago Atitlán, and San

236 Pedro La Laguna were selected as sites with potential for lake sourced water within households,

237 while San Jorge de La Laguna, Tierra Linda, and Agua Escondida were selected as sites with

238 exclusively mountain spring water sources, although one household did report lake water usage

239 at Tierra Linda (3.6\%). Panajachel was thought to be predominantly spring water sourced, as

240 well, however some participants did report lake water use $(n=4,13.3 \%)$, possibly because of

241 proximity to the lake shores compared with the other spring sources. In contrast, far fewer

242 households in San Lucas $(n=44,35.8 \%)$, Santiago $(n=9,26.5 \%)$, and San Pedro $(n=1,6.7 \%)$

243 reported lake water use. To account for this discrepancy, we relied on household reporting of

244 water source instead of physical location for all households. Thus, the final number of

245 households reporting lake water use was 62, while 339 households reported an alternate source.

246 Overall, a greater number of participants were recruited from lake sourced towns

$247(53.4 \%)$ as compared with spring sourced towns (46.6\%), in anticipation of a proportion of the

248 lake sourced town households actually having spring sources. The mean age of participants was

$24934.2 \pm 16.9$ months with a median of 36.0 months- girls were slightly older at $35 \pm 16.5$ months

250 and boys at $33.5 \pm 17.4$.

251

There was a significant difference of BMI between male and female children $(\mathrm{t}$-statistic $=$

$252-2.4413, \mathrm{p}=0.015)$ with males having an increased BMI $(17.0 \pm 3.2)$ relative to females $(16.2 \pm$

253 3.3) (Table S1). Overall the BMI is above the WHO mean for both genders for the mean age of

254 the study $(35 \pm 16.4$ months and $33.5 \pm 17.5$ months, for males and females, respectively). There

255 was significant variation across communities (Table S2) in height, weight, and BMI, mirroring

256 the significant variation in age and distribution of gender across communities. As we relied on

257 healthcare professionals serving different target populations at their point of service, recruitment 
258 by age and sex was highly variable (Figure S1). However, Figure 2A-D illustrates the WHO

259 (age-weighted) z-score for BMI (A, B) and height-for-age (C, D) divided according to gender, 260 with a lower than average profile for height-for-age and above average distribution for age 261 weighted BMI.

262

263

264

265

266

267

268

269

270

271

272

273

274

275

276

277

278

279

280

\section{Household water sources and usage}

Respondents were asked to disclose all known sources of household water. In Table 1, the percentage of total households in each community reporting each type of water source are illustrated, such that the totals for each community do not add up to $100 \%$, but rather reflect the frequencies of usage of various sources across communities. Although more households were recruited from towns that had a potential lake water source, the number of households using spring water $(36.5 \%)$ was twice as high as the households reporting lake water usage $(15.5 \%)$. Interestingly, in addition, $21.3 \%$ of households designated bottled water usage and approximately half the houses cited direct municipal water usage (48.6\%), with some clarifying that as either lake or spring and others uncertain. Other designated sources of water reported included schools and hospitals. Lake water usage varied across municipalities with known lake sources- with San Lucas Tolimán households reporting the highest at $35.8 \%$, followed by Santiago (26.5\%), Panajachel (13.3\%), and San Pedro (6.7\%). Notably, Santiago de Atitlán reported $50 \%$ bottled water usage.

Household water treatment was notable with $77.3 \%$ households designating point of use treatment with boiling being the most common (41.4\%), followed by various kinds of filters clay (12.2\%), carbon (11.5\%), candle (2.7\%), sand (2.0\%), cloth filter (7.8\%), and unknown (2.0\%). Treatment with sodium hypochlorite or bleach was the least commonly used technique (3.0\%). Table 2 illustrates the breakdown of treatment types across each community. Notably, 
281 the lowest proportion of household treatment rate was in Santiago (29.4\%), with the majority of 282 those using boiling techniques (17.5\%), followed by cloth filter (5.9\%). San Jorge had the 283 highest percentage of households reporting treatment (96\%). Not surprisingly, Santiago 284 households, with lowest percentages of treatment, were also at higher risk for frequent episodes 285 of diarrhea $(\mathrm{OR}=8.78, \mathrm{z}$-stat $=4.343, \mathrm{p}<0.0001)$ and fever $(\mathrm{OR}=6.39$, z-stat $=4.002, \mathrm{p}=$ 286 0.0001), relative to all other households.

Figure 3 illustrates the breakdown of treatment types across Giardia negative and

288 Giardia positive cases. The presence of any household treatment was protective against Giardia 289 presence or absence $(\mathrm{OR}=2.5, \mathrm{z}$-stat $=4.72, \mathrm{p}<0.008)($ Table 3). When categories of treatment 290 were further broken down and analyzed through logistic regression, the only significance 291 identified was for sand filters $(O R=5.77, z$-stat $=2.34, p=0.0195))$ with a net harmful effect; 292 however, the limited sample size $(n=8)$ was concentrated in one town (San Lucas), giving little 293 confidence in that observation of significant correlation. While there was no significant 294 protection or harm $(\mathrm{p}<0.05)$ offered by other individual treatments, our sample size may have 295 not been large enough to tease apart protection or harm for each particular treatment, given that $2967.5 \%$ of households with treatment, utilized more than one treatment type. A higher proportion 297 of positive Giardia cases with use of cloth filters indicates they may provide a false sense of 298 security if not combined with other more effective treatments. These findings suggest that 299 municipal level chlorination combined with household use of gravity -fed filters or boiling could 300 substantially reduce the risk of fecal protozoa for children under 5.

301 Other uses for household water that could result in routes of ingestion included use of 302 untreated household water for washing of dishes $(57.6 \%$ overall, with $76.5 \%$ respondents in 303 Santiago, 85\% in San Pedro, 66.7\% in Panajachel, 57.7\% in San Lucas, 53.3.\% in Tierra Linda, 
$30444.0 \%$ in San Jorge, and 25\% in Agua Escondida) and for rinsing of fruits and vegetables (40.4\%

305 overall, with $76.5 \%$ respondents in Santiago, 53.3.\% in Tierra Linda, 51.7\% in San Pedro,

$30643.3 \%$ in Panajachel, 43.1\% in San Lucas, $17.3 \%$ in San Jorge, and 10.7\% in Agua Escondida).

307 Other household uses included watering of plants, bathing, cooking and related activities.

308 Sanitation \& Hygiene

309 While this study mainly focused on water sources, usage, and treatment as the main risk

310 factors of enterogenic illnesses in this population, we did attempt to gage sanitation conditions in

311 the home. The vast majority of households (92\%) reported usage of a latrine, as compared with

$3123 \%$ only reporting a toilet available in the home. The remaining $5 \%$ abstained from the question.

313 This trend was consistent across communities; however, there was no increased risk of shedding

314 of Giardia with latrine usage at risk for cross traffic and contamination, $40 \%$ of households also

315 shared latrines with other houses, and $40 \%$ had open access to their latrine. The former did not

316 result in increased risk of Giardia shedding among the children in this study, while children in

317 households with open access to the toilet did have 2.0 times the risk of shedding Giardia $(\mathrm{OR}=$

$3182.04, \mathrm{z}$-stat $=1.992, \mathrm{p}=0.0464)$. There was no increased risk of frequent diarrhea, vomiting, or

319 fever in households with latrines, shared access, or open access.

320 Prevalence of Giardia and Cryptosporidium in Children 5 years and Younger

321 Overall, the total prevalence of parasite shedding was $12.2 \%$ with a prevalence of

322 Giardia shedding of 9.7\% (M 9.3\%, F 10.8\%) and of Cryptosporidium shedding of 2.5\% (M

$3230.9 \%$, F 2.2\%). A number of risk factors for positive tests for Giardia emerged - including

324 increased age, low z-score for height and lack of any household water treatment (Table 3). There

325 was increased risk of Giardia infection for child ages 3 to 5 as compared with under 3 years of 
326

327

328

329

330

331

332

333

334

335

336

337

338

339

340

341

342

343

344

345

346

347 the kits - the Triage kit did not detect Giardia in 50\% of the samples (11/22) that had a positive

age $(\mathrm{OR}=3.36, \mathrm{z}$-stat $=2.781 \mathrm{p}=0.0054)$, as well as low $\mathrm{z}$-score for height $(\mathrm{OR}=2.28, \mathrm{z}$-stat $=$ $2.225, \mathrm{p}=0.0216$ for those with a $\mathrm{z}$-score of -2 or less).

Lack of any form of household treatment of water $(\mathrm{OR}=2.5, \mathrm{z}$-stat $=2.492, \mathrm{p}=0.012)$

posed an increased risk factor for shedding of Giardia cysts by the child, both suggesting a direct link with water source and a need to expand and improve outreach around WASH interventions in the region as an effective means to reduce exposures in the household.

Prevalence of shedding of Giardia and Cryptosporidium by communities is depicted in

Figure 4. Infections with each organism were approximately equally distributed among boys and girls. There were two cases of co-infection with Entamoeba histolytica and Giardia lamblia, but no cases of co-infection with Cryptosporidium. Tierra Linda had a particularly high prevalence, notable for a mountain spring sourced town; indeed, there was a 7.8 greater odds chance of becoming infected with Giardia if living in Tierra Linda as compared with other times $(\mathrm{OR}=$ $7.8, \mathrm{z}$-stat $=4.48, \mathrm{p}<0.0001)$. Although other sources of fecal organisms cannot be ruled out, we detected issues with filters in the associated nursery school with health worker outreach so results were affected by contamination of the school water source (Table S3, fecal coliforms were elevated in filtrate). We communicated concerns back to community contacts to ensure filters and containers were decontaminated, cleaned, and replaced properly.

\section{Comparison across kits and with screening by microscope}

In comparing the performance of the two purchased ELISA kits, 140 Triage results were compared with the 401 Chek kits. Six of the Triage kits (4.29\%) were invalid when run, while only 1 of the Chek produced an invalid result (0.25\%). There was very poor correlation between 
348 test via the Chek kit. Seven samples in the kit comparison tested positive for Cryptosporidium

349 via the Chek kits; none of these were positive via the Triage kits.

350 Of the 401 samples to submitted to the laboratory, 268 were also examined by fecal

351 flotation and microscope, including 110 of which all had Triage analysis. Five samples had eggs

352 of Ascaris lumbricoides, seven had cysts Iodamoeba butschlii, seven had cysts of Blastocystis

353 hominis, sixteen had cysts Entamoeba coli with 1 additional sample of trophozoites (three

354 presented in samples with other organisms), and one sample had Chilomastix mesnili

355 trophozoites. Three of these had G. lamblia cysts (A. lumbricoides in two samples, E. coli, and B.

356 hominis) and one had co-infection with Cryptosporidium (Entamoeba coli), but all of these are

357 not necessarily pathogenic. E. coli, I. butschlii, and C. mesnili are common hominid intestinal

358 inhabitants, while $A$. lumbricoides can cause intestinal blockage and impair growth in children.

359 The pathogenicity of $\mathrm{B}$. hominis is unclear.

360 Six microscope samples identified Giardia; the five cysts were also identified by the

361 CHEK kit, while the one trophozoite positive sample was not. Only one of the cyst samples was

362 identified by the Triage kit.

363 Household Reported Illness in Children 5 years and Younger

364 Household lake water use emerged as a risk factor, among household characteristics for

365 frequently reported gastrointestinal symptoms, e.g. at the very least several times per month, (

$366 \mathrm{OR}=2.5, \mathrm{z}-\mathrm{stat}=3.07, \mathrm{p}=0.0021$ for diarrhea; $\mathrm{OR}=4.4$, z-stat $=3.65, \mathrm{p}=0.0003$ for

367 vomiting; and $\mathrm{OR}=2.6, \mathrm{z}$-stat $=3.0, \mathrm{p}=0.0028$ for fever), despite not being a predictor of

368 shedding of protozoa in this study. Table 4 provides totals for each separate outcome in exposed

369 and unexposed groups, the odds ratio, and other measures of association for binary logistic

370 regression, for each separate potential gastrointestinal symptom or outcome. In households with 
371 lake water use, children were twice as likely to have frequent episodes of diarrhea with $40 \%$ of

372 households utilizing lake water reporting diarrhea at least once a month as compared with $16 \%$

373 for non-lake sourced households. Similar trends were observed for fever (28\% versus $11 \%$ ) and 374 vomiting (19\% versus $7 \%)$.

375 Figure 5A-C depicts the full distribution self-reported frequency of diarrhea (A),

376 vomiting $(\mathbf{B})$, and fever $(\mathbf{C})$ across communities, with three levels of frequency: symptom

377 reported frequently (monthly or greater), sometimes (annually or greater), and never. There was

378 also an increased risk by location for symptoms. Santiago had an increased risk both diarrhea

$379(\mathrm{OR}=8.8, \mathrm{z}$-stat $=4.343, \mathrm{p}<0.0001)$ and fever $(\mathrm{OR}=6.4, \mathrm{z}$-stat $=4.002, \mathrm{p}=0.0001)$,

380 compared with other locations. Tierra Linda also had an increased risk of diarrhea $(\mathrm{OR}=2.5$, z-

381 stat $=2.155, \mathrm{p}=0.0311)$ in children 5 years and younger, compared to other locations. As can be

382 seen in Figure 5A-C, the vast majority of households across communities reported diarrhea and

383 fever at least several times per year, and approximately half the households reported vomiting at

384 least several times per year.

\section{Discussion}

386 This study substantially contributes to the dearth of published works characterizing

387 gastrointestinal illness among indigenous lakeside communities at Atitlán. It reveals a strong

388 association of household use of water and reporting of frequent adverse gastrointestinal

389 symptoms of diarrhea, vomiting (Table 4). Profound to note was the frequency all three

390 gastrointestinal symptoms were reported greater than monthly and at least several times per year,

391 across all locations. In contrast, there was no noticeable increased risk with self-reported

392 sanitation patterns (e.g. type of household sanitation and degree of access), although $40 \%$ of

393 households reported open or shared access. A major limitation of the study was the inability to 
394 simultaneously assess a wide range of enteric pathogens, including viruses such as rotavirus, or

395 bacteria such as cholera or salmonella. The lower than expected infection rates of common

396 protozoal diseases (12.2\%) cannot sufficiently explain the high prevalence of $40 \%$ of more than

397 monthly episodes of diarrheal disease in this region. This prevalence corroborates findings and

398 rates reported by the Ministry of Health (INE, 2018). These results also potentially represent a

399 better resourced portion of the indigenous population at the lake, e.g. those seeking out health

400 services or connected to existing programs. While there was no direct connection between source

401 of household water as a risk factor and shedding of parasites, there was a substantial increased

402 risk of frequent gastrointestinal illness in children 5 years and younger from household use of

403 lake water (odds ratio risk of 2.5, 4.4, and 2.6; p-values of $0.0021,0.0003$, and 0.0028 , for

404 diarrhea, vomiting, and fever, respectively), suggesting the importance of addressing lake water

405 quality as a major risk factor for the health of children at Lake Atitlán. In addition, households

406 with open access to latrines had an increased risk of Giardia shedding among the children in this

407 study $(\mathrm{OR}=2.04, \mathrm{z}$-stat $=1.992, \mathrm{p}=0.0464)$, suggesting sanitation practices and hygiene could

408 be central to reducing exposure to fecal protozoa.

409 Our rates of Giardia and Cryptosporidium were lower than previously reported in the

410 region. Close to $50 \%$ in preschoolers in three Guatemalan Western highland pre-schools were

411 actively shedding fecal protozoa and $43 \%$ of children had multiple parasitic infections (Jensen et

412 al., 2009). 32\% of children in villages around Atitlán presenting with gastrointestinal symptoms

413 were shedding Cryptosporidium oocysts (Bentley et al., 2004; Laubach et al., 2014),. A

414 prevalence of $21.5 \%$ for Giardia duodenalis and 19.8\% for Entamoeba histolytica was

415 determined after fecal samples were collected to field visits to clinics in the highlands and

416 riparian zones (Soto-Méndez et al., 2016). It is important to note that our study examined mostly 
417 "healthy" children. Those not presenting with symptoms at the time of fecal sampling may have

418 exhibited a greater association of protozoal shedding with lake water use if sampled when 419 symptomatic.

420 Previous work comparing the Triage Micro Parasite Panel with traditional ovum and 421 parasite microscopy (O \& P)for the detection of G. lamblia, C. parvum, and E. histolytica 422 indicated a much higher sensitivity and specificity than observed in this study. When utilized to 423 screen known positive and negative stool samples with O \& $\mathrm{P}$, including trichrome and modified 424 acid-fast stains, the sensitivity and specificity of the test for listed pathogens was $95.8 \%$ and $42597.4 \%$; 98.3\% and 99.7\%; and 96.0\% and 99\%, respectively (Garcia et al., 2000). In this study, a 426 number of samples with discrepancies with positive Triage samples were found to be true 427 positives when tested by an alternative method of immunofluorescence or enzyme immunoassay 428 (EIA) panel. We note, following the manufacturer's instructions for sample preparation, the 429 dilution of the Triage sample was double that of the final Chek kit sample. The 430 underperformance of the Triage kit could be related to a lower concentration of parasite, 431 particularly in asymptomatic individuals. Indeed, in symptomatic and ill patients, testing 432 negative by microscopy alone, (Sharp et al., 2001) and in outbreak scenarios (Swierczewski et 433 al., 2012), where fecal shedding and load individuals is high, and when prevalence of disease is 434 high, these rapid bedside kits may be particularly useful tools in tagging samples for further 435 analysis beyond $\mathrm{O} \& \mathrm{P}$. However, in our study, of the 17 Giardia positive cases detected by Chek 436 kit, only $29.4 \%$ were positive by O\& $\mathrm{P}$, indicated a utility for this test in tiered screening, 437 particularly when individuals are asymptomatic at the moment or when overall suspected 438 prevalence is lower. Previous work comparing detection in known positive and negative samples 439 by the Chek kit platform, along with a number of other enzyme linked or rapid PCR tests, 
440 indicated a sensitivity and specificity of $100 \%, 94 \%$, and $100 \%$ and $100 \%$, for G, lamblia and C

441 parvum, re these (Van den Bossche et al., 2015); an alternative work compared the test to

442 microscopy in 200 stool samples from clinical cases and found $93.3 \%$ and $99.4 \% ; ; 87.6 \%$ and

$44398.9 \%$, respectively for sensitivity and specificity of these two organisms (Alexander et al.,

444 2013). Our results here indicate that in routine surveillance and screening of asymptomatic

445 individuals the Chek kit may provide a more robust platform compared to traditional O\&P

446 microscopy, not just the advantage of time and decreased level of skill. Indeed, the Chek assay

447 outperformed quantitative polymerase chain reaction as a rapid point-of-care diagnostic for

448 infants in Bangladesh (Kabier et al. 2018).

449 Our study sample size and distribution had some limitations in examining potential

450 differences between communities as demonstrated by the physical exam data. Recruitment was

451 not necessarily reflective of population size of the respective town. Santiago, Panajachel, and

452 San Lucas have some of the larger and most concentrated populations in the region (estimated

453 between 20-50K) (Ferráns et al., 2018), depending on exact boundaries and time of the year,

454 while the other villages are notably smaller. Our recruitment was directly through community

455 partners and health care workers. This permitted greater participant trust and retention, as well as

456 the confidential distribution of results and follow up care. Previous community-based work has

457 demonstrated direct engagement with households around filter use or other intervention methods

458 can drastically improve water quality at point of use in the household (Roegner et al., 2016).

459 However, this approach has its limitations and sampling bias as we had uneven participant

460 distribution among locations (Figure 1). Additionally, the sampling was biased toward

461 individuals already engaged within programs that address or advocate WASH and/or means to

462 seek out health services (Omarova et al., 2018; Setty et al., 2019). 
implemented. Our education handouts included considerations about risk through other avenues

(Appendix A), and future outreach work in the region should incorporate recommendations

beyond exposure directly at the tap.

It is also important to acknowledge that lake water usage was lower than anticipated among lake-sourced towns (in particular, San Pedro, Santiago, and San Lucas). This studydid not evaluate parent or guardian knowledge and attitudes regarding lake water safety. It is unclear whether the lower levels of lake water usage reflects households as viewing lake water as 'unsafe' and seeking out other sources (for example, we note the high use of bottled water), lack 474 of information about from where municipal water is actually derived, or truly lower levels of 475 lake water distribution in towns. A study conducted in Santiago Atitlán regarding the drinking water beliefs showed that more than half of the participants considered the lake's water to be

477 dirty due to the contaminants that entered the lake (Nagata et al., 2011). The sources of 478 contamination included trash, rain, bacteria and germs, laundry run-off and boats. Even though

479 historically people have mistrusted chlorinated water, a slight majority of the participants 480 preferred drinking chlorinated water as they considered it could help kill bacteria and germs, 481 clean the water, prevent illness and prevent diarrhea. In comparison, those who did not like 482 chlorinated water mentioned they disliked the taste and smell, they considered it could cause 483 illness, it was not effective and that it was too strong (Nagata et al., 2011). Thus, a major limitation of our study was reliance on self-reporting of water source. We 485 lacked the ability to geo-reference household sites with municipal officials to confirm exact 
486 water source piped to the household. Both for confidentiality purposes and uncertainty of validity

487 of georeferencing, this additional tracing step was omitted from the study, but future work is

488 needed to 1) delineate and verify water sources for neighborhoods and households from these

489 lakeside towns and 2) capture perceptions in community about safety of various water sources. A

490 higher than expected level of household lake water usage was found in Panajachel. With known

491 high levels of arsenic in the well water in Panajachel, we are uncertain as to whether behavioral

492 changes have occurred due to viewing spring water as 'unsafe,' lack of knowledge about source

493 of municipal water, or whether this reflects a true trend. Similarly, the simultaneous high usage

494 of bottled water in Santiago, along with the lowest levels of household water treatment, and the

495 higher reported frequency of gastrointestinal illness in children under 5 years of age, lends

496 serious concern to the potential false sense of security and perceptions about the safety of locally

497 bottled water sources. Future work must include testing of local bottled water sources and

498 education campaigns about precautions with uncertified labels.

499 It is also very likely that other household WASH practices play a large role in rates of

500 protozoal infections, and broad WASH best practices must be further targeted to further reduce

501 the incidence. Indeed, households with open access to latrines had an increased risk of Giardia

502 shedding among the children in this study $(\mathrm{OR}=2.04$, z-stat $=1.992, \mathrm{p}=0.0464)$, suggesting

503 sanitation practices and hygiene could be targeted to reduce this risk. Alternative passive

504 sampling means, such as collection from home latrines (LaHue et al., 2018), may more

505 accurately capture exposure and incidence in the home environment, but it would obfuscate

506 access to studying exposure in children 5 years of age and younger. Regardless of route of

507 exposure, if protozoal infections persist, malabsorption of nutrients may occur and result in

508 stunting (Mmbaga and Houpt, 2017; Mohammadkhah et al., 2018; Solomons et al., 2015). 
509 Possible explanations for increased risk among participants 3 years of age and older $(\mathrm{OR}=3.4$, $510 \mathrm{z}$-stat $=3.12, \mathrm{p}=0.0058$ ) include increased risk from direct ingestion of water from tap without

511 treatment (as opposed through nursing or formula prepared with boiling water), increased risk of

512 exposure through fecal-oral routes or other household sources as the child becomes more mobile, 513 exposure to other multiple water sources outside the household, or the pathophysiology of

514 Giardia infections. The risk for stunting and developmental growth necessitates a closer look at 515 the incidence of infection rates by multiple organisms, not just shedding of specific protozoa, 516 among children under 5 years of age (Certad et al., 2017; Mmbaga and Houpt, 2017;

517 Mohammadkhah et al., 2018). Furthermore, animals (cats, dogs, chickens) were widely reported 518 with access to the porch or house, indicating a need to further investigate into zoonotic illnesses 519 (Budge et al., 2019; Ercumen et al., 2017). The methods used in this study focused on Giardia, Cryptosporidium, and Entamoeba species most commonly carried by humans, but other species

521 can easily infect children and vulnerable groups.

522

523

524 525 526 527 528 529
Much lower rates of household water treatment in the region have been previously reported (Nagata et al., 2011; Roegner et al., 2016). While the results of reported household treatment varied substantially by community, we found that1) communities and households without additional household level treatment are at increased risk of protozoal infections in children 5 years of age and younger; and 2) communities with lower rates of household treatment of water also report higher incidence of household gastrointestinal illness in children 5 years of age and younger. These findings emphasize the importance of both dissemination of filters for household use and education about proper filter care and use, as well as distribution of chlorination and boiling protocols. Furthermore, it should be emphasized that cloth filters are insufficient treatment methods on their own. Finally, these household approaches combined with 
532 enforcement of state-mandated chlorination treatment at municipal plants could go a long way in

533 reducing both prevalence of childhood protozoal infections and gastrointestinal illness around

534 the lake. While beyond the scope of this study, future work could more closely examine the

535 relative efficacy of various treatment practices individually and together in the context of the

536 household longitudinally in reduction of pathogens, including protozoa, bacteria, and viruses,

537 and prevention of gastrointestinal illness outcomes, particularly in young children.

538 Finally, sewage inflow into the lake is largely untreated with direct inflow at Panajachel,

539 Santa Catarina, and Santa Cruz, with high levels of nitrogen and phosphorus entering and only

540 minimal treatment at other locations, thereby still contributing substantial nutrient loads

541 (Chandra et al., 2013). Rivers San Francisco and Quiscab, surrounding Panajachel to the east and

542 west, also drain the basin bringing wastewater discharged in the upper highlands into the lake, as

543 well. Previous work in the region has documented Escherichia coli at lake water at these

544 outflows at 1800 and 10,000 MPN/100 mL, respectively. Similar values were observed at

545 various beaches and lake sites routinely frequented for recreation (Roegner et al., 2017). In the

546 same study at San Pedro, household tap water, prior to treatment, had levels of fecal coliforms

547 and E. coli, exceeding permissible levels by the World Health Organization. The local

548 governmental group Authority for the Sustainable Management of the Lake Atitlan Basin and its

549 Surroundings (AMSCLAE) has recently reported similarly elevated levels of coliform at other

550 sites around the lake (AMSCLAE, 2017), and historical data also supports lake wide

551 contamination at intake, point sources, and nonpoint sources (Castellanos et al., 2002). While

552 beyond the scope of this study to evaluate pathogens in source waters and efficacy of any

553 employed treatment, we did take single time point samples for each municipality at the drinking

554 water intake from the lake or mountain source and then from a tap source, post variable levels of 
555 treatment (Table S3). Levels were typically lower at the intake than previously reported testing

556 near discharge sites. However, levels in untreated lake waters were typically indicative of a

557 moderate to severe risk for adverse effects based on WHO guidelines for recreational use.

558 Treated tap water taken from the lake were typically orders of magnitude lower in risk, further

559 supporting the reduced risk in the presence of household treatment found this study. Given the

560 limited time points and samples, we did not include these findings in our overall presentation of

561 this work. Yet, overall, it is clear that widespread wastewater discharge in the region can be

562 directly linked to declining source water quality with severe implications for the gastrointestinal

563 health and development of children in the region. Not only is adequate treatment and

564 infrastructure for drinking water needed to adequately augment children's health and

565 development in the region, the underlying issue of wastewater contamination and discharge into

566 the lake must be addressed.

\section{Conclusions}

568 Our study contributes to a better understanding of the gastrointestinal health burden in 569 young children from indigenous communities around Lake Atitlán, Sololá, Guatemala. Our

570 results underscore the relationship to water quality, and provide potential areas for

571 implementing WASH interventions and educational outreach in the region to better meet

572 indigenous community needs. Key findings for public health officials and water resource

573 managers include:

574 - Improved household level treatment appears to reduce risk, but is not uniformly

$575 \quad$ distributed. 
576

577

578

579

580

581

582

583

584

585

586

587

588

589

590

591

592

593

594

595

596

597

- Lake water, untreated water usage, and contaminated bottled water are all key points of risk to address, particularly with respect to reducing adverse gastrointestinal health outcomes in children 5 years and younger.

- Both treatment and lower infection rates may be misrepresented in our population already engaged through existing health provider or NGO avenues.

- The prevalence of protozoal infections cannot account for the incidence and frequency of gastrointestinal illness in the region, and other enteropathogens must be examined in future studies.

- Although incidence of shedding of Giardia and Cryptosporidium was lower than previously reported, it still represents a substantial burden with implications for malabsorption, stunting, and other chronic developmental effects, particularly in otherwise asymptomatic children.

- Additional education is needed about other avenues of contamination, including but not limited to rinsing plates or produce with untreated water, risk from animals, and sanitation risks from open latrine access.

- The ELISA Chek Kit utilized in this study appears to be a useful tool for quick and straightforward diagnostic evaluation of Giardia lamblia and Cryptosporidium parvum in feces in the region, particularly in patients not currently presenting with symptoms

- Future investigations should explore the risk from locally bottled water, perceptions that different households have with respect to drinking water risk, and how that influences behaviors or choices. In addition, other pathogens of fecal origin, including bacteria and viruses should be examined with the relationship of risk to water quality and source. 
599 We thank the Rotary Club at Lake Atitlán, Panajachel, for donating the anti-protozoal

600 medications used to treat positive children under the supervision of a healthcare provider. We

601 also thank the Association of Amigos del Lago de Atitlán, and Vivamos Mejor for logistical and

602 personnel support, as well as Laboratorio La Asunción for help with diagnostics and screening

603 by microscope. Finally, the project would not have been possible without the enthusiastic

604 involvement of Audrey Ward (Medical Program Coordinator) and Mayan Families staff and

605 volunteers; Dr. Anita Tuch and the San Pedro Centro de Salud medical staff; Dr. Juan Manuel

606 Chuc and the Hospitalito de Atitlán medical staff; Dr. Rafael Tun and the San Lucas Hospital

607 medical staff--- their cooperation, coordination, and care are greatly appreciated. Funding for this

608 project was made possible by a Seed Grant for International Activities from the University of

609 California, Davis.

610 References

611 Bentley, C., Laubach, H., Spalter, J., Ginter, E., Jensen, L., 2004. Relationship of

612 cryptosporidiosis to abdominal pain and diarrhea in Mayan Indians. Rev Inst Med Trop

613 Sao Paulo. 46 (4), 235-237. https://doi.org/10.1590/S0036-46652004000400011

614 Bird, P., Bastin B., Klass, N., Crowley, E., Agin, J., Goins, D., Bakken, H., Lingle, C.,

615 Schumacher, A., 2020. Evaluation of the $3 \mathrm{M}^{\mathrm{TM}}$ Petrifilm ${ }^{\mathrm{TM}}$ Rapid E. coli/Coliform Count

616 Plate for the Enumeration of E. coli and Coliforms: Collaborative Study, First Action:

617 2018.13, Journal of AOAC INTERNATIONAL.103(2): 513-522,

$618 \quad$ https://doi.org/10.1093/jaocint/qsz013

619 Brezonik, P.L., Fox, JL., 1974. The limnology of selected Guatemalan Lakes. Hydrobiologia.

620 45(4), 467-487. https://doi.org/10.1007/BF00012032 
621 Broussard, J.D., 2003. Optimal fecal assessment. Clin Tech Small Anim Pract. 18(4): 218-230.

622

623

624

625

626

627

628

629

630

631

632

633

634

635

636

637

638

639

640

641

642

643

https:// 10.1016/S1096-2867(03)00076-8

Budge, S., Hutchings. P., Parker, A., Tyrrel, S., Tulu, T., Gizaw, M., Garbutt, C., 2019. Do

domestic animals contribute to bacterial contamination of infant transmission pathways? Formative evidence from Ethiopia. Journal of Water and Health. 17(5), 655-669. https://doi.org/10.2166/wh.2019.224

Castellanos, E., Girón, N., López, B., Álvarez, M., España, M., 2002. Diagnóstico de la Calidad del Agua del Lago Atitlán, y de la Subcuenca del Río Panajachel, Guatemala. Report for The Nature Conservancy and USAID.

Certad, G., Viscogliosi, E., Chabé, M., Cacciò, S.M., 2017. Pathogenic Mechanisms of Cryptosporidium and Giardia. Trends Parasitol. 33(7), 561-576.DOI: 10.1016/j.pt.2017.02.006

Chandra, S., Dix, M., Rejmankova. E., Mosquera, V., Giron, N., Heyvaert, A. 2013. Current Ecological State of Lake Atitlan and the Impact of Sewage Inflow: A Recommendation to Export Sewage out of the Basin to Restore the Lake. Available online:_http://bvc.ceaatitlan.org.gt/105/1/Reporte\%20Cientifico\%20-En-.pdf

Chen, D., Rivera-Andrade, Á., González, J., Burt, D., Mendoza-Montano, C., Patrie, J., Max, James., 2017. Prevalence of risk factors for noncommunicable diseases in an indigenous community in Santiago Atitlan, Guatemala. Rev Panam Salud Pública. 41, e7. http://dx.doi.org/10.26633/RPSP.2017.7

Corman, J.R., Carlson, E., Dix, M., Girón, N., Roegner, A., Veselá, J., Chandra, S., Elser, J.J., Rejmánková, E.,2015. Nutrient dynamics and phytoplankton resource limitation in a deep tropical mountain lake. Inland Waters. 5(4), 371-386. DOI: $\underline{10.5268 / \mathrm{IW}-5.4 .843}$ 
644 Ercumen, A., Pickering, A.J., Kwong, L.H., Arnold, B.F., Parvez, S.M, Alam, M., Sen, D., 645 Sharmin, I., Kullman, C., Chase, C., Ahmed, R., Unicomb, L., Luby, S.P., Colford, J.M., 646 2017. Animal Feces Contribute to Domestic Fecal Contamination: Evidence from E. coli 647 Measured in Water, Hands, Food, Flies, and Soil in Bangladesh. Environ. Sci Technol. 648 51(15), 8725-8734. DOI: $\underline{10.1021 / \text { acs.est.7b01710 }}$

649 Farthing, M.J, G., Mata, L., Urrutia, J.J., Kronmal, R.A., 1986. Natural history of Giardia 650 infection of infants and children in rural Guatemala and its impact on physical growth. Am J Clin Nutr. 43(3), 395-405. DOI: 10.1093/ajcn/43.3.395

652

653

654

655

656

657

658

659

660

661

662

663 664

665
Ferráns, L., Cifuentes, C.S., Avellán, T., Dornack, C., Hettiarachchi, H., 2018. Wastewater Management in the Basin of Lake Atitlan: A Background Study. UNU-FLORES Working Paper Series 6. Dresden, United Nations University Institute for Integrated Management of Material Fluxes and of Resources (UNU-FLORES).

Garcia, L.S., Shimizu, R.Y., Bernard, C.N., 2000. Detection of Giardia lamblia, Entamoeba histolytica/Entamoeba dispar, and Cryptosporidium parvum antigens in human fecal specimens using the triage parasite panel enzyme immunoassay. J Clin Microbiol. 38(9):3337-40. DOI: 10.1128/JCM.38.9.3337-3340.2000.

INE. Defunciones por sexo, según edad y causas de muerte, año 2018. https://www.ine.gob.gt/ine/estadisticas/bases-de-datos/vitales/ (Accessed 22.03.20)

INE, 2018. https://www.ine.gob.gt/ine/vitales/(Accessed 22.03.20)

Jensen, L.A., Marlin, J.W., Dyck, D.D., Laubach, H.E., 2009. Prevalence of multigastrointestinal infections with helminth, protozoan and Campylobacter spp. in Guatemalan children. J Infect Dev Ctries. 3(3), 229-234. DOI: $\underline{10.3855 / j i d c .41}$ 
666 Kabir, M., Ahmed, E., Hossain, B., Alam, M., Ahmed, S., Taniuchi, M., Gilchrist, C.A., Houpt, 667 E.R., Faruque, A.S.G., Petri, Jr, W.W., Haque, R., 2018. Giardia/Cryptosporidium QUIK 668 CHEK Assay Is More Specific Than Quantitative Polymerase Chain Reaction for Rapid 669 Point-of-care Diagnosis of Cryptosporidiosis in Infants in Bangladesh. Clin Infect Dis. 670 67(12): 1897-1903. DOI: 10.1093/cid/ciy372

671 LaHue, N., Alexander, K.A., 2018. Pit Latrines: A Noninvasive Sampling Strategy to Assess 672 Fecal Pathogen Occurrence in Low Resource Communities. J Community Health. 673 43,1155-1160. DOI: $10.1007 / \mathrm{s} 10900-018-0535-8$

674 Laubach, H.E., Bentley, C.Z., Ginter, E.L., Spalter, J.S., Jensen, L.A., 2014. A study of risk 675 factors associated with the prevalence of Cryptosporidium in villages around Lake 676 Atitlan, Guatemala. Braz J Infect Dis. 8(4),319-323. https://doi.org/10.1590/S1413$677 \underline{86702004000400008}$

678 MSPAS. Departamento de Epidemiología, 2019.

679 http://epidemiologia.mspas.gob.gt/files/Publicaciones\%202019/Boletines\%202019/BOE $680 \quad$ PISE52.pd (Accessed 22.03.20)

681 Mmbaga, B.T., Houpt, E.R., 2017. Cryptosporidium and Giardia Infections in Children: A 682 Review. Pediatr Clin North Am. 64(4), 837-850. DOI: 10.1016/j.pcl.2017.03.014 683 Mohammadkhah, A.I., Simpson, E.B., Patterson, S.G., Ferguson, J.F.,2018. Development of the 684 Gut Microbiome in Children, and Lifetime Implications for Obesity and Cardiometabolic 685 Disease. Children. 5(12), 160. https://doi.org/10.3390/children5120160

Nagata, J.M., Barg, F.K., Valeggia, C.R., Bream, K.D.,2011. Coca-Colonization and Hybridization of Diets among the Tz'utujil Maya. Ecol Food Nutr. 50(4), 297-318. https://doi.org/10.1080/03670244.2011.568911 
689 Nagata, J.M., Valeggia, C., Smith, N.W., Barg, F.K., Guidera, M., Bream, K.D.W.,2011.

690

691

692

693

694

695

696

697

698

699

700

701

702

703

704

705

706

707

708

709

710

Criticisms of chlorination: Social determinants of drinking water beliefs and practices among the Tz'utujil Maya. Rev Panam Salud Pública. 29 (1), 9-16. DOI: 10.1590/S102049892011000100002

Nagata, J.M., Valeggia, C.R., Barg, F.K., Bream, K.D., 2009. Body mass index, socio-economic status and socio-behavioral practices among Tz'utujil Maya women. Econ Hum Biol. 7(1): 96-106. https://doi.org/10.1016/j.ehb.2009.02.002

Newhall, C.G., Paull, C.K., Bradbury, J.P., Higuera-Gundy, A., Poppe LJ., Self, S., Bonar, N., Ziagos, J., 1987. Recent geologic history of lake Atitlán, a caldera lake in western Guatemala. Journal of Volcanology and Geothermal Research. 33(1-3), 81-107. https://doi.org/10.1016/0377-0273(87)90055-2

Omarova, A., Tussupova, K., Berndtsson, R., Kalishev, M., Sharapatova, K. 2018. Protozoan Parasites in Drinking Water: A System Approach for Improved Water, Sanitation and Hygiene in Developing Countries. Int J Environ Res Public Health. 15(3), 495. https://doi.org/10.3390/ijerph15030495

Orozco, M.,2017. El Estado Actual Del Lago Atitlán Sololá, Guatemala, Universidad del Valle.

Poder, T.H., He, J., 2015. The Role of Ethnic and Rural Discrimination in the Relationship Between Income Inequality and Health in Guatemala. Int J Health Serv. 45(2), 285-305. https://doi.org/10.1177/0020731414568509

Rejmánková, E., Komárek. J., Dix, M., Komárková, J., Girón, N.,2011. Cyanobacterial blooms in Lake Atitlan, Guatemala. Ecology and Management of Inland Waters. 41(4), 296-302. https://doi.org/10.1016/j.limno.2010.12.003 
711 Roegner, A., Ochaeta, G., Bocel, E., Ogari, Z., Pfotenhaeur, B., Rejmánková, E., 2016.

712

713

714

715

716

717

718

719

720

721

722

723

724

725

726

727

728

729

730

731

732

733

Employing CBPR to investigate function, utility, and longevity of household filters to improve potable water quality for indigenous peoples at Lake Atitlán, Guatemala: a pilot study with San Pedro de La Laguna. Energ. Ecol. Environ. 2, 95-113. https://doi.org/10.1007/s40974-016-0045-4

RStudio Team 2017. http://www.rstudio.com/ (accessed 09-28-17)

Setty, K., Cronk, R., George, S., Anderson, D., O’Flaherty, G,. Bartram, J., 2019. Adapting Translational Research Methods to Water, Sanitation, and Hygiene. Int J Environ Res Public Health. 16(20),4049. DOI: 10.3390/ijerph16204049

Sharp, S.E., Suarez, C.A., Duran, Y., Poppiti, R.J., 2001. Evaluation of the Triage Micro Parasite Panel for detection of Giardia lamblia, Entamoeba histolytica/Entamoeba dispar, and Cryptosporidium parvum in patient stool specimens. J Clin Microbiol: 39(1):332-4.DOI: 10.1128/JCM.39.1.332-334.2001. PMID: 11136793

Solomons, N.W., Vossenaar, M., Chomat, A.M., Doak, C.M., Koski, K.G., Scott, M. E., 2015. Stunting at birth: recognition of early-life linear growth failure in the western highlands of Guatemala. Public Health Nutr. 18(10), 1737-1745. https://doi.org/10.1017/S136898001400264X

Soto-Méndez, M.J., Romero-Abal, M.E., Schümann, K., Gil, Á., Solomons, N.W. 2017. Normative Fecal Calprotectin Concentrations in Guatemalan Preschoolers Are High Relative to Children Reported Elsewhere. J Pediatr Gastroenterol Nutr. 64(2): 238-244. DOI: $10.1097 / M P G .0000000000001241$

Soto-Méndez, M.J., Aguilera, C.M., Mesa, M.D., Campaña-Martín, L., Martín-Laguna, V., Solomons, N.W., Schümann., Gil, Á., 2016. Interaction of Giardia intestinalis and 
734 Systemic Oxidation in Preschool Children in the Western Highlands of Guatemala. $\underline{\mathbf{J}}$

735 Pediatr Gastroenterol Nutr.63(1), 118-122. DOI: $\underline{\text { 10.1097/MPG.0000000000000891 }}$

736 Swierczewski, B., Odundo, E., Ndonye, J., Kirera, R., Odhiambo, C., Oaks, E., 2012.

737 Comparison of the Triage Micro Parasite Panel and Microscopy for the Detection of

738 Entamoeba histolytica/Entamoeba dispar, Giardia lamblia, and Cryptosporidium parvum

739 in Stool Samples Collected in Kenya. J Trop Med: 2012:564721. DOI:

$740 \quad 10.1155 / 2012 / 564721$.

741 Youn, S., Kabir, M., Haque, R., Petri, W.A., 2009. Evaluation of a Screening Test for Detection

742 of Giardia and Cryptosporidium Parasites. J Clin Microbiol. 47(2), 451-452.

743 DOI: $\underline{10.1128 / \mathrm{JCM} .01736-08}$

744

745 
Figure 1

Figure 1. Map of study area with distribution of male and female participants at each community location

There were a total of 215 and 186 male and female participants, respectively. Stars represent towns thought to predominantly derive water from spring sources, while dots represent towns with a portion of water drawn from the lake prior to dispersal to households.

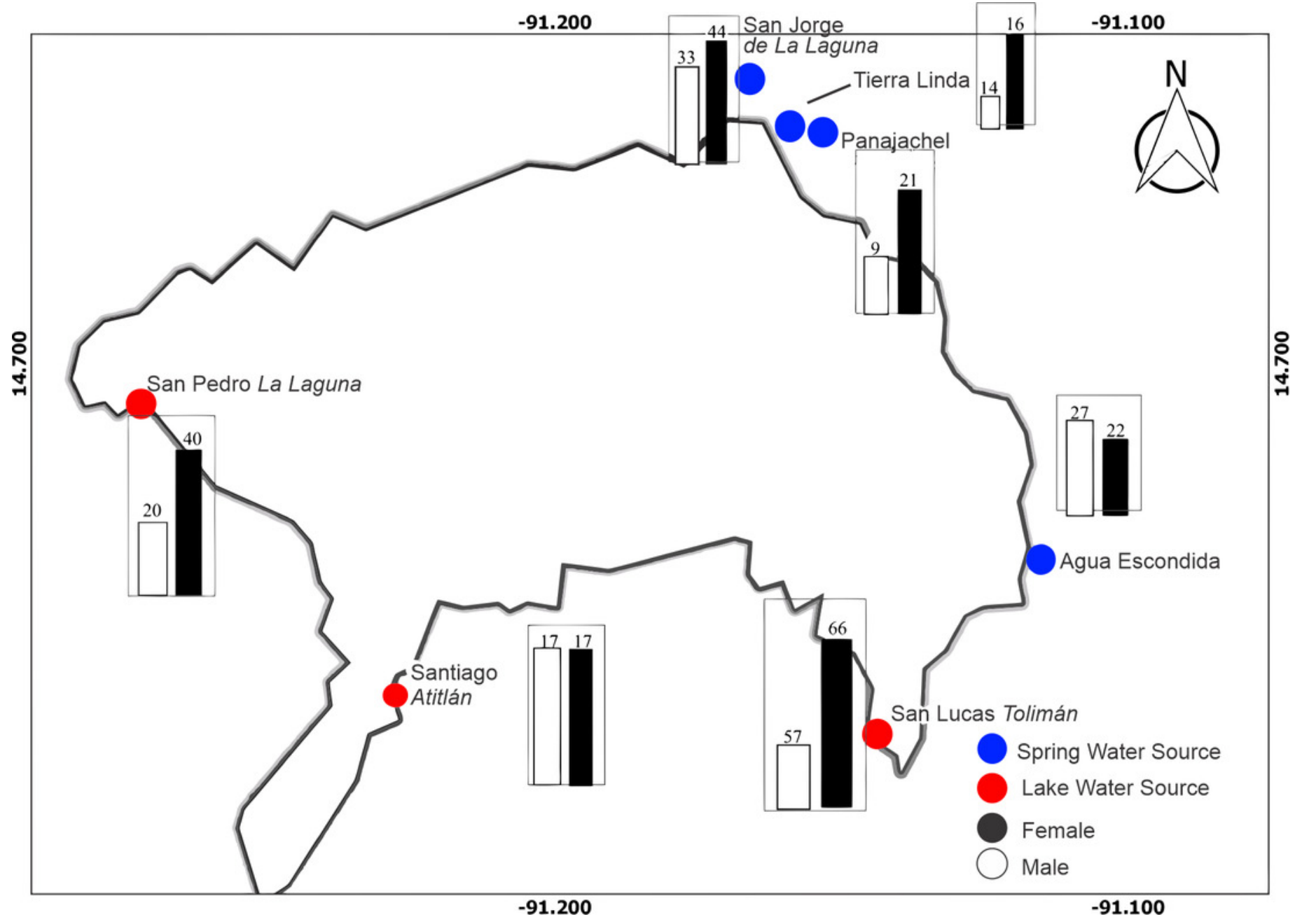




\section{Figure 2}

Figures 2A-2D. Gender distribution curves of age-weighted z-scores for BMI and height.

Determined according to the WHO guidance (WHO 2006). Grey bars represent male distribution (total male participants, $n=215$ ), and black curves represent female distribution (total female participants, $\mathrm{n}=186$ ), with $\mathrm{BMI}$ on the top panel $(\mathrm{A}, \mathrm{B})$ and height depicted below $(C, D)$. Male BMI was significantly increased compared to female BMI (t-stat $=-2.4413$, $p=0.015)$, and there was significant variation of height $(p=0.0000687)$, weight $(p=0.0198)$, and BMI $(p=0.0123)$, across communities, by ANOVA, which mirrored significant variation across in age and gender across communities. 

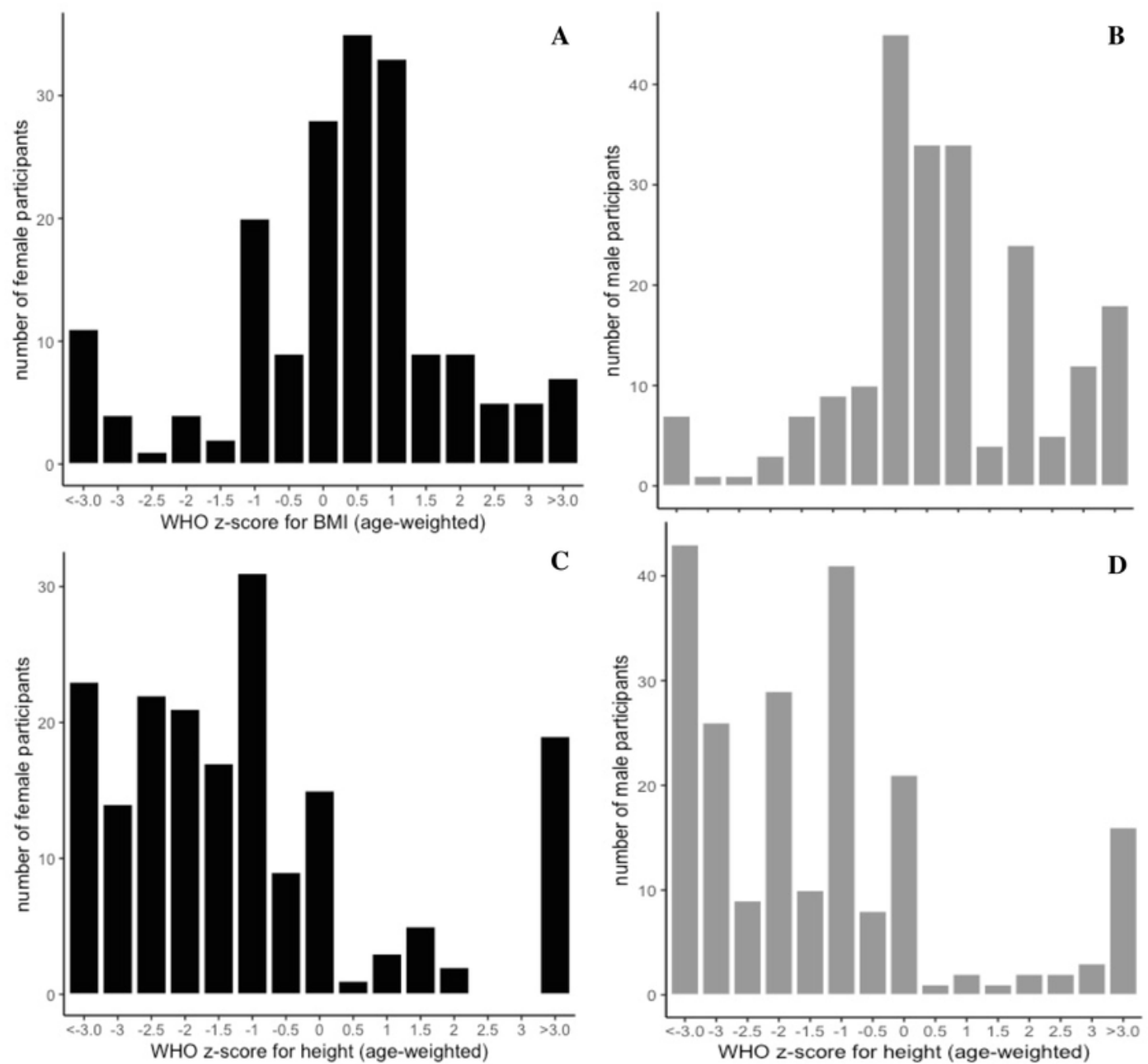


\section{Figure 3}

Figure 3. Household reported \% treatment distributed by Giardia test outcome.

Logistic regression was used to identify significant characteristics of Giardia positive households. Respondents could select as many treatment types that applied. Gravity-fed filters included candle, carbon, ceramic pot, and sand filters. Santiago (29.4\% for any treatment) and Tierra Linda (63.2\% for any treatment) also had a higher percentage of households with frequent episodes of diarrhea and fever (as defined as at least once per month, or greater). Treatment of any kind* was protective against shedding of Giardia (OR = 2.5, z-stat $=4.72, p<0.008)$. "Sand filters increased risk for Giardia $(O R=6.1, z$-stat $=2.49$, $p<0.048)$. The analysis included a total of 35 Giardia positive samples and 366 Giardia negative samples. 

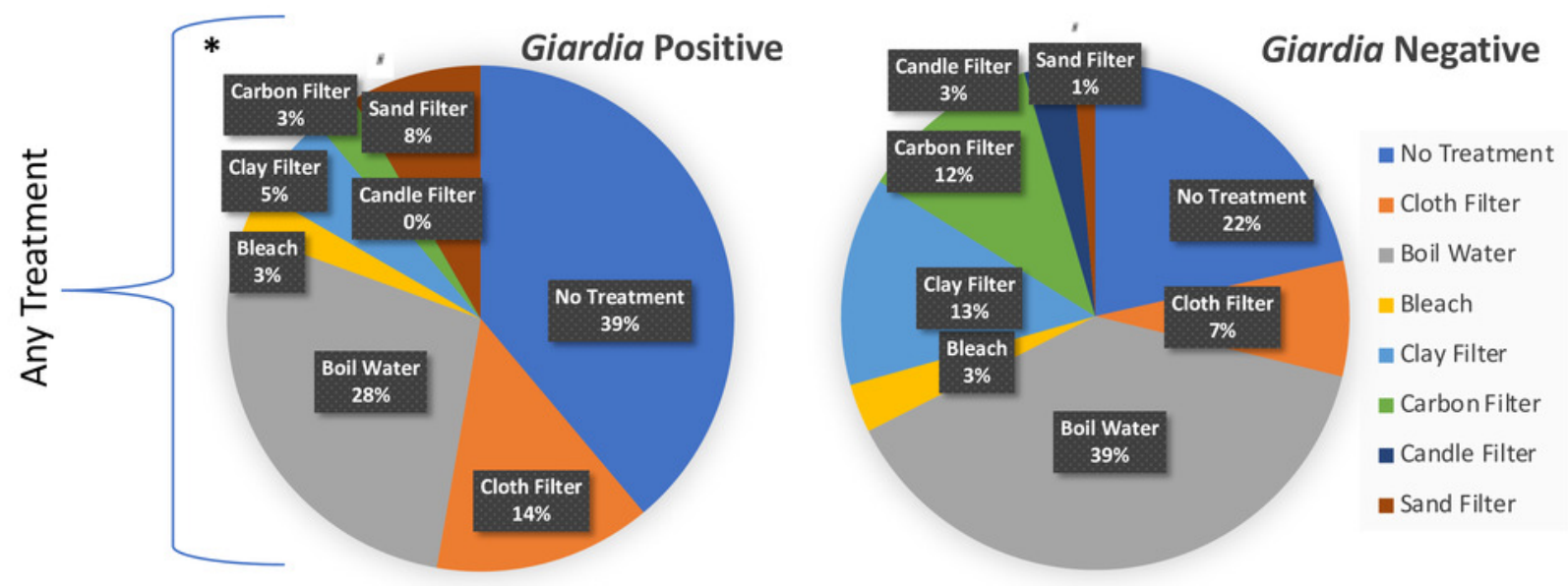


\section{Figure 4}

Figure 4A-B. Distribution of Giardia (A) and Cryptosporidium (B) cases by community among total number of participants.

Percent cases by location, indicating community prevalence, is placed atop the bar graph. No cases of comorbidity with both parasites were found. $*$ indicates significantly higher prevalence was found in Tierra Linda compared to other towns ( $p<0.001)$. There was 7.8 greater odds of becoming infected with Giardia if living in Tierra Linda as compared with other towns ( $z$-stat $=4.48, p<0.0001$ ). The analysis included a total of 35 Giardia positive samples and 366 Giardia negative samples, as well as 10 Cryptosporidium positive and 391 negative samples. 
A

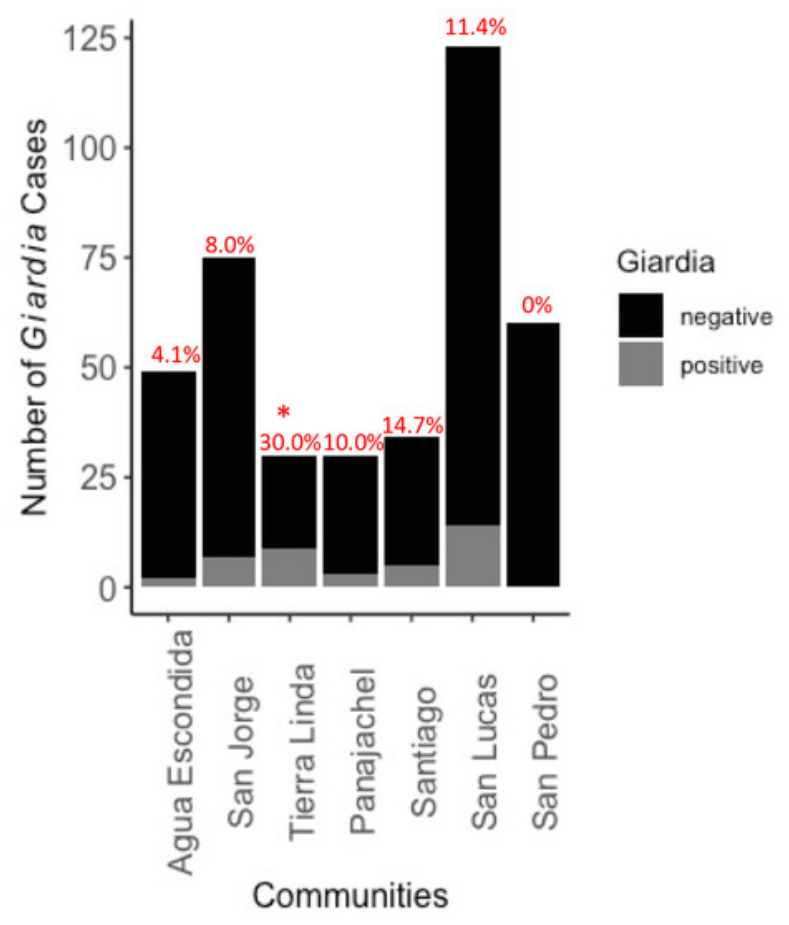

B

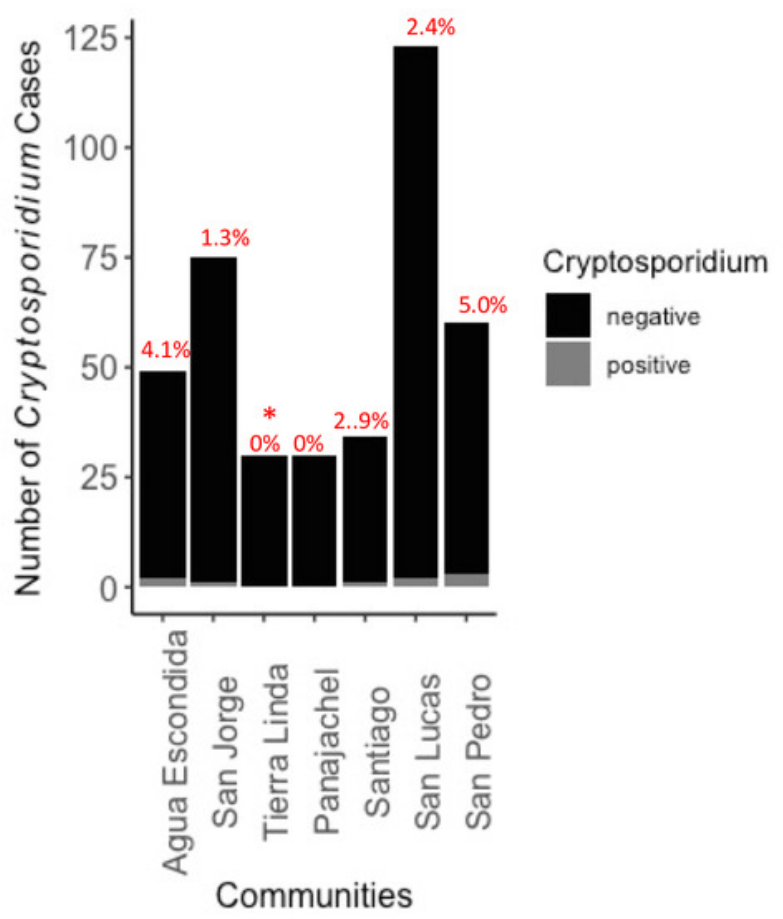




\section{Figure 5}

Figure 5. Proportions of households reporting diarrhea (A), vomiting (B), and fever (C) across locations.

. The legend denotates the proportion of household reporting never, sometimes, and frequent (greater than once a month) episodes of each symptom in children five years and younger in each household. \# denotes significance of $p \leq 0.001$ of risk compared to other locations. * denotes significance of $<0.05$ compared to other locations. Santiago had 8.8 times the risk for diarrhea ( $z$-stat $=4.343, p<0.0001$ ) and 6.4 for fever ( $z$-stat $=4.002, p=$ 0.0001 ) in children 5 years and younger. Tierra Linda had an increased risk 2.5 for diarrhea (z-stat $=2.155, p=0.0311$ ), compared to other locations. Sample sizes of self-reporting for diarrhea, vomiting, and fever were 387,385 , and 395 , respectively. 


\section{A Frequency of Diarrhea Reported Across} Households

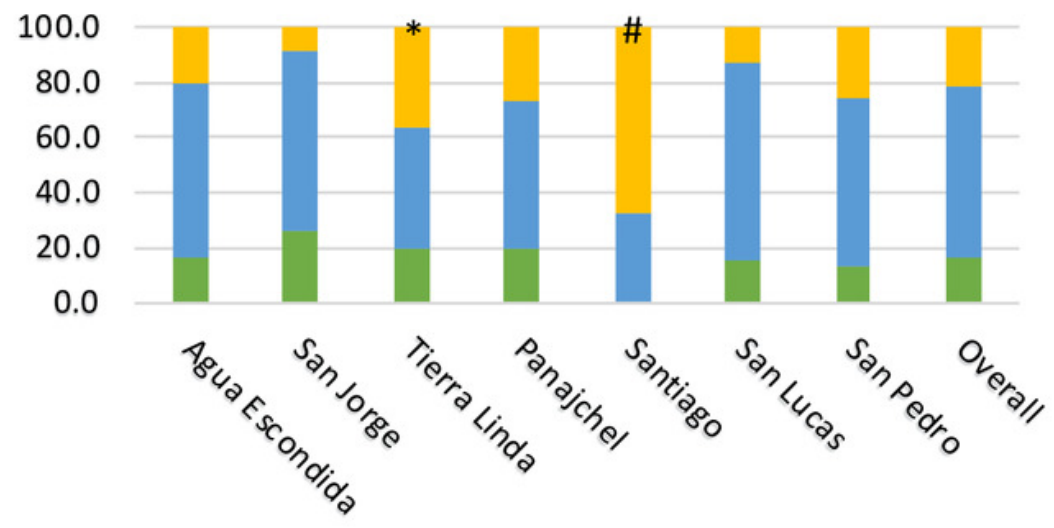

\section{aiarrhea never $\square$ Diarrhea sometimes Diarrhea frequent B Frequency of Vomiting Reported Across} Households

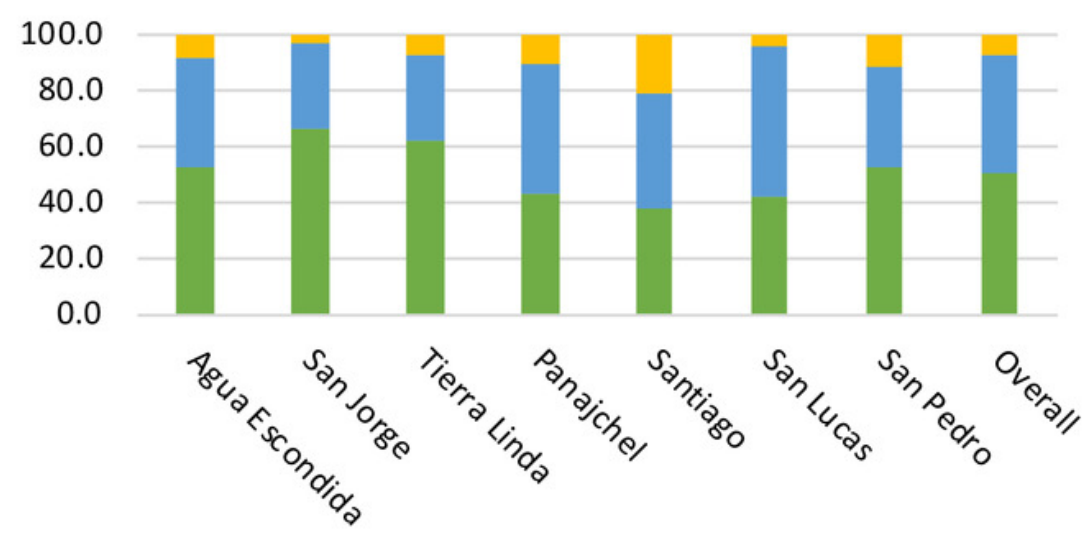

vomiting never $\square$ Vomiting sometimes $\quad$ Vomiting frequent C Frequency of Fever Reported Across Households

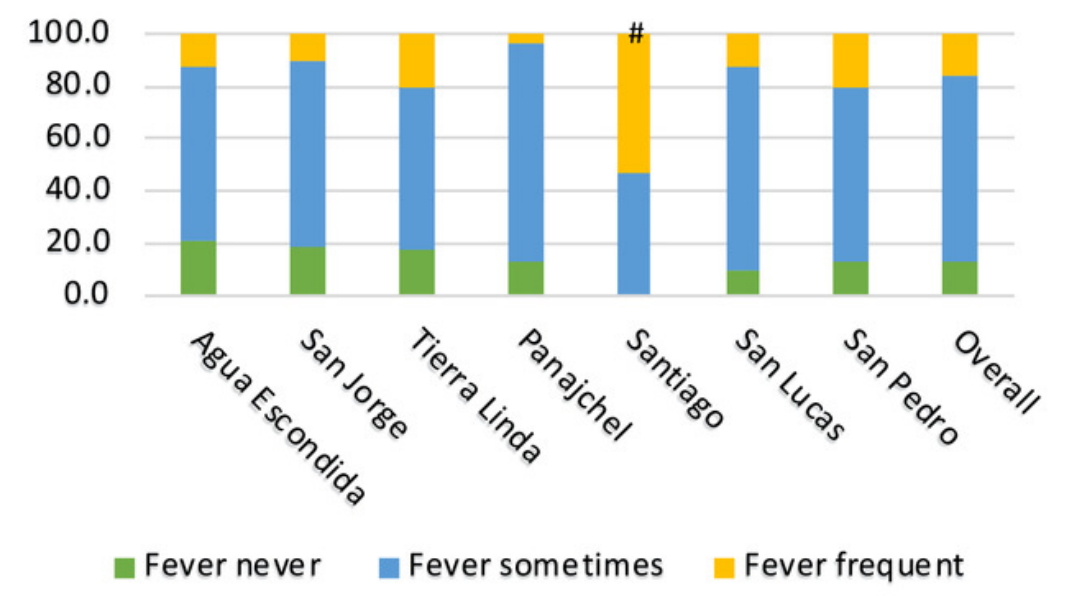




\section{Table $\mathbf{1}$ (on next page)}

Lake, spring, municipal and bottled water \% household reported usage by community.

Totals do not equal $100 \%$ as respondents could select more than one water source. The majority of respondents reported municipal-sourced water, which could not be verified as a lake or spring source or mixed in towns with more than one municipal source because addresses were not taken and surveys were anonymized. Data analysis was based on reported source type and not on an assumed water source per community. 


\begin{tabular}{|c|c|c|c|c|}
\hline Location & Lake (\%) & $\begin{array}{c}\text { Spring } \\
\mathbf{( \% )}\end{array}$ & $\begin{array}{c}\text { Municipal } \\
\mathbf{( \% )}\end{array}$ & $\begin{array}{c}\text { Bottled } \\
\mathbf{( \% )}\end{array}$ \\
\hline \hline All & 15.5 & 36.5 & 48.6 & 21.3 \\
\hline $\begin{array}{c}\text { Agua } \\
\text { Escondida }\end{array}$ & 0.0 & 82.1 & 78.6 & 7.1 \\
\hline Panajachel & 13.3 & 23.3 & 46.7 & 20.0 \\
\hline Santiago & 26.5 & 0.0 & 23.5 & 50.0 \\
\hline San Jorge & 0.0 & 56.0 & 38.7 & 6.7 \\
\hline San Lucas & 35.8 & 20.3 & 49.6 & 29.3 \\
\hline San Pedro & 6.7 & 8.5 & 76.7 & 28.3 \\
\hline Tierra Linda & 3.6 & 83.3 & 16.7 & 0.0 \\
\hline
\end{tabular}

Table 1. Lake, spring, municipal and bottled water \% household reported usage by community. Totals do not equal $100 \%$ as respondents could select more than one water source. The majority of respondents reported municipal-sourced water, which could not be verified as a lake or spring source or mixed in towns with more than one municipal source because addresses were not taken and surveys were anonymized. Data analysis was based on reported source type and not on an assumed water source per community. 


\section{Table 2 (on next page)}

Household reported \% treatment overall and as distributed within each community.

Household respondents could select as many treatment types that applied. Treatment of any

kind $^{*}$ was protective against shedding of Giardia $(R R=0.29, p<0.0001$, z-stat $=4.42, O R=$ $0.24)$. 


\begin{tabular}{|c|c|c|c|c|c|c|c|c|c|}
\hline $\begin{array}{c}\text { Water } \\
\text { Location }\end{array}$ & $\begin{array}{c}\text { Treatment } \\
\text { Boiling }\end{array}$ & $\begin{array}{c}\text { Cloth } \\
\text { Filter }\end{array}$ & Bleach & $\begin{array}{c}\text { Clay } \\
\text { Filter }\end{array}$ & $\begin{array}{c}\text { Carbon } \\
\text { Filter }\end{array}$ & Candle & Sand & Unspecified & Any Filter \\
\hline \hline All & $\mathbf{7 7 . 3 *}$ & 41.4 & 7.8 & 3.0 & 12.2 & 11.5 & 2.7 & 2.0 & 2.0 \\
\hline $\begin{array}{c}\text { Agua } \\
\text { Escondida }\end{array}$ & $\mathbf{8 9 . 3}$ & 82.1 & 0.0 & 7.1 & 10.7 & 14.3 & 3.6 & 0.0 & 0.0 \\
\hline Panajachel & $\mathbf{8 0 . 0}$ & 40.0 & 0.0 & 10.0 & 0.0 & 33.3 & 0.0 & 0.0 & 28.6 \\
\hline Santiago & $\mathbf{2 9 . 4}$ & 17.6 & 5.9 & 0.0 & 2.9 & 0.0 & 2.9 & 0.0 & 0.0 \\
\hline San Jorge & $\mathbf{9 6 . 0}$ & 36.0 & 22.7 & 1.3 & 9.3 & 21.3 & 1.3 & 0.0 & 4.0 \\
\hline San Lucas & $\mathbf{7 8 . 0}$ & 39.8 & 8.1 & 1.6 & 17.9 & 4.1 & 1.6 & 6.5 & 2.4 \\
\hline San Pedro & $\mathbf{8 3 . 3}$ & 33.3 & 3.3 & 1.7 & 25.0 & 15.0 & 8.3 & 0.0 & 36.0 \\
\hline Tierra Linda & $\mathbf{6 3 . 3}$ & 50.0 & 0.0 & 3.3 & 3.3 & 6.7 & 3.3 & 0.0 & 0.0 \\
\hline \hline
\end{tabular}

\section{3}

Table 2. Household reported \% treatment overall and as distributed within each community. Household respondents could select as many treatment types that applied. Treatment of any kind* was protective against shedding of Giardia $(\mathrm{RR}=0.29, \mathrm{p}<$ $0.0001, \mathrm{z}$-stat $=4.42, \mathrm{OR}=0.24$ ) 


\section{Table 3 (on next page)}

Demographic and household risk factors for Giardia and measures of association.

Relative risk is calculated from binary logistic regression outcomes and indicate correlation, not causation. Categories listed represent those with significance greater than $p<0.05$. Three years of age was selected as a cut-off point due to marked turnover of gut microbiota until approximately 3 months, with remodeling of the intestinal lining. Height-adjusted zscore deviations of greater than 1.5 were examined as significant from normal. 


\begin{tabular}{|c|c|c|c|c|c|c|}
\hline $\begin{array}{c}\text { Case Incidences of Giardia in Children } \\
\text { Presenting with and without Identified Risk } \\
\text { Factors }\end{array}$ & \multicolumn{2}{|c|}{ Outcome } & \multicolumn{4}{|c|}{ Measures of Association } \\
\cline { 2 - 7 } & Giardia positive & $\begin{array}{c}\text { Odds } \\
\text { ratio }\end{array}$ & $\begin{array}{c}\text { 95\% confidence } \\
\text { interval }\end{array}$ & $\begin{array}{c}\text { Z- } \\
\text { statistic }\end{array}$ & $\begin{array}{c}\text { Significance } \\
\text { level }\end{array}$ \\
\hline Risk Categories & $\mathrm{Y}$ & $\mathrm{N}$ & & & & \\
\hline$\geq 3$ years in age* & 28 & 199 & 3.3568 & 1.4299 to 7.8805 & 2.781 & $\mathrm{p}=0.0054$ \\
\hline$<3$ years in age & 7 & 167 & & & \\
\hline height-adj z-score $\leq-2^{*}$ & 23 & 167 & 2.2839 & 1.1032 to 4.7282 & 2.225 & $\mathrm{p}=0.0216$ \\
\hline height-adj z-score $>-2$ & 12 & 199 & & & \\
\hline no household treatment* & 14 & 77 & 2.5022 & 1.2161 to 5.1481 & 2.492 & $\mathrm{p}=0.012$ \\
\hline household treatment & 21 & 366 & & & \\
\hline
\end{tabular}

Table 3. Demographic and household risk factors for Giardia and measures of association. Odds ratios were calculated for binary logistic regression outcomes and indicate correlation, not causation. Categories listed represent those with significance greater than $p$ $<0.05$. $*$ indicates the category with increased risk. Three years of age was selected as a cut-off point due to marked turnover of gut microbiota until approximately 36 months [23], with remodeling of the intestinal lining. Height-adjusted z-score deviations of greater than 1.5 were examined for increased risk and $z$-scores of less than or equal to -2.0 were identified as significant. The analysis included a total of 35 Giardia positive samples and 366 Giardia negative samples. 


\section{Table 4 (on next page)}

Identified household risk factor for gastrointestinal outcomes and measures of association for binary outcomes of frequent episodes of symptoms reported at household level

Relative risk is calculated from binary logistic regression outcomes and indicate correlation, not causation. Categories listed represented those with significance greater than $p<0.05$. 


\begin{tabular}{|c|c|c|c|c|c|c|}
\hline \multirow{3}{*}{$\begin{array}{l}\text { Case Incidences of Gastrointestinal Outcomes } \\
\text { in Children in Lake Water and Non- Lake } \\
\text { Water Households } \\
\text { Household Groups }\end{array}$} & \multicolumn{6}{|c|}{ Outcome } \\
\hline & \multicolumn{2}{|c|}{$\begin{array}{l}\text { Frequent } \\
\text { Diarrhea } \\
\end{array}$} & \multicolumn{2}{|c|}{$\begin{array}{l}\text { Frequent } \\
\text { Vomiting } \\
\end{array}$} & \multicolumn{2}{|c|}{$\begin{array}{c}\text { Frequent } \\
\text { Fever } \\
\end{array}$} \\
\hline & Y & $\mathrm{N}$ & $\mathrm{Y}$ & $\mathrm{N}$ & $\mathrm{Y}$ & $\mathrm{N}$ \\
\hline Exposed to Lake Water & 23 & 39 & 12 & 49 & 18 & 43 \\
\hline Not Exposed to Lake Water* & 62 & 263 & 17 & 307 & 46 & 288 \\
\hline Odds ratio & \multicolumn{2}{|c|}{2.5} & \multicolumn{2}{|c|}{4.4} & \multicolumn{2}{|c|}{2.6} \\
\hline $95 \%$ confidence interval & \multicolumn{2}{|c|}{1.3938 to 4.4900} & \multicolumn{2}{|c|}{1.9909 to 9.8243} & \multicolumn{2}{|c|}{1.3928 to 4.9315} \\
\hline z-statistic & \multicolumn{2}{|c|}{3.073} & \multicolumn{2}{|c|}{3.651} & \multicolumn{2}{|c|}{3.0} \\
\hline Significance level & \multicolumn{2}{|c|}{$\mathrm{p}=0.0021$} & \multicolumn{2}{|c|}{$\mathrm{p}=0.0003$} & \multicolumn{2}{|c|}{$\mathrm{p}=0.0028$} \\
\hline
\end{tabular}

Table 4. Identified household risk factor for gastrointestinal outcomes and measures of association for binary outcomes of frequent episodes of symptoms reported at household level. Odd ratio were calculated after binary logistic regression indicated significance $(\mathrm{p}<0.05)$. A total of 62 households self-reported lake water usage, and 339 households indicated an alternate source. There were some non-responses for the questions regarding gastrointestinal illness, with a total of 387, 385, and 395 recorded responses for diarrhea, vomiting, and fever, respectively. * Indicates not exposed to lake water in household, although may be exposed through other locations Frequent was defined as at least monthly. 